\title{
UTJECAJ GNOJIDBE DUŠIKOM NA PRINOS I SASTAVNICE PRINOSA SJEMENA NEKIH SORATA PREDIVOG LANA
}

\author{
Jasminka BUTORAC ${ }^{1}$, Milan POSPIŠIL ${ }^{1}$, Zvjezdana AUGUSTINOVIĆ ${ }^{2}$ \\ ${ }^{1}$ Sveučilište u Zagrebu Agronomski fakultet \\ University of Zagreb Faculty of Agriculture \\ ${ }^{2}$ Visoko gospodarsko učilište u Križevcima \\ College of Agriculture at Križevci
}

\begin{abstract}
SAŽETAK
U radu se iznose rezultati postignutog prinosa i sastavnica prinosa sjemena (broj biljaka po $\mathrm{m}^{2}$, broj tobolaca po biljci, broj sjemenki u tobolcu, masa 1000 sjemenki) pet inozemnih sorata predivog lana gnojenih različitim količinama dušika $\left(0,30,60\right.$ i $\left.90 \mathrm{~kg} \mathrm{ha}^{-1}\right)$ primijenjenih u različito vrijeme. Pokusi s predivim lanom provedeni su tijekom tri godine (2008.-2010.) u Zagrebu na eutrično smeđem antropogeniziranom tlu i u Križevcima na pseudogleju obronačnom prema metodi slučajnog bloknog rasporeda u četiri ponavljanja.

$\mathrm{Na}$ osnovi trogodišnjih istraživanja prinosa i sastavnica prinosa sjemena predivog lana utvrđeno je da postoje signifikantne razlike između istraživanih sorata i između primijenjenih količina dušika. Sorte Viking, Venica i Electra ostvarile su veće vrijednosti istraživanih svojstava. Prema dobivenim rezultatima u gnojidbi predivog lana nije potrebno dodavati više od $30 \mathrm{~kg} \mathrm{ha}^{-1}$ dušika.

Ključne riječi: predivi lan, sorte, gnojidba dušikom, prinos sjemena, sastavnice prinosa sjemena
\end{abstract}

\section{UVOD I CILJ ISTRAŽIVANJA}

Pravi trenutak berbe predivog lana ovisi o sorti, o stupnju zrelosti lanene biljke i o namjeni za koju se lan uzgaja. Predivi lan za dobivanje vlakna najčešće se čupa u fazi zeleno-žute zriobe, jer se želi dobiti kvalitetna stabljika (primarni proizvod), te relativno dobro sjeme (sekundarni proizvod). Sjeme još treba dozrijeti procesom „nadozrijevanja“. Predivi lan za dobivanje sjemena se žanje u fazi pune zriobe. U fazi pune zriobe stabljika je svjetlo smeđe boje. Listovi su sa stabljike u potpunosti otpali. Sjeme je smeđe boje i potpuno zrelo. 
Jasminka Butorac i sur.: Utjecaj gnojidbe dušikom na prinos i sastavnice prinosa sjemena nekih sorata predivog lana

U Hrvatskoj ima malo istraživanja koja su se bavila tehnologijom proizvodnje sjemena predivog lana. 50-ih i 60-ih godina 20. stoljeća u Hrvatsku su introducirane europske sorte predivog lana i prva istraživanja provedena se na nizozemskim sortama (P a s k o v i ć, 1957.) 70-ih i 80-ih godina 20. stoljeća proizvodnja sjemena predivog lana zasnivala se na sortama nizozemskog i belgijskog podrijetla (ك̌ i m e t i ć, 1995.). U Hrvatskoj nije nikada zaživjela proizvodnja vlastitog sjemenskog materijala. Kako proizvodnja lana prestaje u Hrvatskoj zatvaranjem pogona za preradu lana $\mathrm{u}$ Črnkovcima krajem 80 -ih godina 20. stoljeća, tako prestaje i dotadašnja sjemenska proizvodnja bazirana na introduciranim sortama.

Za ponovno uvođenje lana na poljoprivredne površine potrebno je istražiti primjereni broj inozemnih sorata $\mathrm{s}$ motrišta njihovih agronomskih, morfoloških i fenoloških svojstava, dakako, paralelno s time i aklimatizacijske sposobnosti na agroekološke uvjete Hrvatske uz primjenu adekvatne agrotehnike. U sjeverozapadnoj Hrvatskoj se posljednjih 10-ak godina provode intenzivna istraživanja u tom pravcu (A n d r a s s y i sur., 2004., B u t o r a c i sur., 2003., 2006a, 2006b, 2009., 2010a, i 2010b, P o s p i š i 1 i sur., 2004., Š u r i n a i sur., 2011. i 2012.).

Današnje komercijalne europske sorte predivog lana su jare sorte prilagođene maritimnoj klimi. Budući da Hrvatska ne raspolaže vlastitim selekcijskim materijalom upućena je na introdukciju stranih sorata predivog lana koje mogu u novonastalim uvjetima izgubiti vrijedna svojstva (A n d r a s s y i sur., 2010., B u t o r a c i sur., 2003., 2004., 2009., 2011., 2012., 2013.).

Cilj ovog rada bio je utvrditi prinos i sastavnice prinosa sjemena pet kultivara predivog lana gnojenih sa različitim količinama dušika primijenjenih u različito vrijeme.

\section{MATERIJALI I METODE}

Tijekom 2008. do 2010. godine provedena su istraživanja s predivim lanom na pokušalištu Agronomskog fakulteta u Zagrebu na eutričnom smeđem antropogeniziranom tlu $\mathrm{i}$ na pokušalištu Visokog gospodarskog učilišta u Križevcima na pseudogleju obronačnom. U pokusu je bilo zastupljeno pet sorata lana koje su vlasništvo četiri selekcijske tvrtke i to: Viking (Cooperative Liniere de Fontaine Cany, Francuska), Viola (Van de Bilt Zaden, Nizozemska), Venica (Agritec, Češka), Agatha i Electra (Cebecco Seeds, Nizozemska). Pokusi su provedeni prema metodi slučajnog bloknog rasporeda u četiri ponavljanja. Veličina osnovne parcele u pokusu iznosila je $10 \mathrm{~m}^{2}$.

Lan je gnojen s različitim količinama dušika $\left(0,30,60\right.$ i $\left.90 \mathrm{~kg} \mathrm{ha}^{-1}\right)$ primijenjenih u različito vrijeme. U prvoj varijanti nije dodan dušik. U drugoj gnojidbenoj varijanti dodan je sav dušik prije sjetve (30 $\mathrm{kg} \mathrm{ha}^{-1}$ dušika). U trećoj gnojidbenoj varijanti $30 \mathrm{~kg}$ $\mathrm{ha}^{-1}$ dušika dodano je prije sjetve, a $30 \mathrm{~kg} \mathrm{ha}^{-1} \mathrm{u}$ jednokratnoj prihrani pri prosječnoj visini biljke od $10 \mathrm{~cm}$, dok je u četvrtoj gnojidbenoj varijanti $30 \mathrm{~kg} \mathrm{ha}^{-1}$ dodano prije sjetve, a po $30 \mathrm{~kg} \mathrm{ha}^{-1}$ u prihrani pri prosječnoj visini biljaka od 10 i $20 \mathrm{~cm}$. 
Lan je ručno ubran u fazi pune zriobe (ovisno o godini istraživanja i lokaciji u razdoblju od 10. do 20. 7.) na površini od $1 \mathrm{~m}^{2}$. Na uzorku od $1 \mathrm{~m}^{2}$ određen je broj biljaka, broj tobolaca po biljci, broj sjemenki u tobolcu, masa 1000 sjemenki i prinos sjemena. Svi prikupljeni podaci obrađeni su analizom varijance, a razlike između srednjih vrijednosti testirane su Duncan-ovim testom (DMRT).

\section{REZULTATI ISTRAŽIVANJA I RASPRAVA}

Statistički opravdane razlike između istraživanih sorata i između različitih gnojidbi dušikom utvrđene su za većinu istraživanih svojstva. U 2008. godini nije bilo signifikantnih razlika između sorata za broj sjemenki po tobolcu i za masu 1000 sjemenki u Križevcima, te između različitih gnojidbi dušikom za broj biljaka na obje lokacije (Tablica 1. i Tablica 2.). U 2009. godini nije bilo signifikantnih razlika između sorata za broj biljaka u Križevcima, te između različitih gnojidbi dušikom za broj biljaka na obje lokacije i masu 1000 sjemenki u Zagrebu (Tablica 3., Tablica 4.).

Tablica 1. Analiza varijance (F vrijednosti) prinosa i sastavnica prinosa sjemena sorata predivog lana $u$ 2008. godini na lokaciji Zagreb

Table 1 Analysis of variance (F-values) for yield and yield components of fibre flax varieties in 2008 at location Zagreb

\begin{tabular}{|c|c|c|c|c|c|}
\hline $\begin{array}{c}\text { Izvori } \\
\text { varijabilnosti }\end{array}$ & $\begin{array}{c}\text { Broj } \\
\text { biljaka }\end{array}$ & $\begin{array}{l}\text { Prinos } \\
\text { sjemena }\end{array}$ & $\begin{array}{c}\text { Broj tobolaca } \\
\text { po biljci }\end{array}$ & $\begin{array}{c}\text { Broj sjemenki u } \\
\text { tobolcu }\end{array}$ & $\begin{array}{l}\text { Masa } 1000 \\
\text { sjemenki }\end{array}$ \\
\hline $\begin{array}{l}\text { Source of } \\
\text { variations }\end{array}$ & $\begin{array}{l}\text { Number } \\
\text { of plants }\end{array}$ & $\begin{array}{l}\text { Seed } \\
\text { yield }\end{array}$ & $\begin{array}{c}\text { Number of } \\
\text { capsules } \\
\text { per plant }\end{array}$ & $\begin{array}{c}\text { Number of seed } \\
\text { per capsules }\end{array}$ & $\begin{array}{l}1000 \text { seed } \\
\text { weight }\end{array}$ \\
\hline $\begin{array}{l}\text { Sorta }(\mathrm{S}) \\
\text { Variety }\end{array}$ & $26,81 *$ & $49,59 *$ & $37,69 *$ & $4,75^{*}$ & $5,65^{*}$ \\
\hline $\begin{array}{l}\text { Gnojidba } \\
\text { dušikom (GD) } \\
\text { Nitrogen } \\
\text { fertilization }\end{array}$ & $0,20 \mathrm{~ns}$ & $38,00 *$ & $49,12 *$ & $39,58 *$ & $8,78 *$ \\
\hline $\begin{array}{l}\text { Interakcija } \\
\text { (SxGD) } \\
\text { Interaction }\end{array}$ & $0,04 \mathrm{~ns}$ & $0,01 \mathrm{~ns}$ & $0,01 \mathrm{~ns}$ & $0,01 \mathrm{~ns}$ & $0,34 \mathrm{~ns}$ \\
\hline
\end{tabular}

Oznake u tablici: * - statistička opravdanost, ns - nema statističke opravdanosti

Designation used in Table: ${ }^{*}$ - statistically significant effect, $n s-$ no statistically significant effect 
Tablica 2. Analiza varijance ( $F$ vrijednosti) prinosa i sastavnica prinosa sjemena sorata predivog lana $u$ 2008. godini na lokaciji Križevci

Table 2 Analysis of variance ( $F$-values) for yield and yield components of fibre flax varieties in 2008 at location Križevci

\begin{tabular}{lccccc}
\hline $\begin{array}{c}\text { Izvori } \\
\text { varijabilnosti } \\
\begin{array}{c}\text { Source of } \\
\text { variations }\end{array}\end{array}$ & $\begin{array}{c}\text { Broj } \\
\text { biljaka } \\
\text { Number } \\
\text { of plants }\end{array}$ & $\begin{array}{c}\text { Prinos } \\
\text { sjemena } \\
\text { Seed } \\
\text { yield }\end{array}$ & $\begin{array}{c}\text { Broj tobolaca } \\
\text { po biljci } \\
\text { Number of } \\
\text { capsules per plant }\end{array}$ & $\begin{array}{c}\text { Broj sjemenki u } \\
\text { tobolcu } \\
\text { Number of seed } \\
\text { per capsules }\end{array}$ & $\begin{array}{c}\text { Masa 1000 } \\
\text { sjemenki } \\
1000 \text { seed } \\
\text { weight }\end{array}$ \\
\hline $\begin{array}{l}\text { Sorta (S) } \\
\text { Variety }\end{array}$ & $3,02^{*}$ & $100,95^{*}$ & $3,52^{*}$ & $2,35 \mathrm{~ns}$ & $1,08 \mathrm{~ns}$ \\
\hline $\begin{array}{l}\text { Gnojidba } \\
\text { dušikom (GD) }\end{array}$ & $0,78 \mathrm{~ns}$ & $50,57^{*}$ & $10,28^{*}$ & & $2,58^{*}$ \\
$\begin{array}{l}\text { Nitrogen } \\
\text { fertilization }\end{array}$ & & & & $2,87^{*}$ \\
\hline $\begin{array}{l}\text { Interakcija } \\
\text { (SxGD) }\end{array}$ & $0,25 \mathrm{~ns}$ & $0,37 \mathrm{~ns}$ & $0,46 \mathrm{~ns}$ & $1,33 \mathrm{~ns}$ & $0,21 \mathrm{~ns}$ \\
Interaction & & & & \\
\hline
\end{tabular}

Oznake u tablici: ${ }^{*}$ - statistička opravdanost, ns - nema statističke opravdanosti

Designation used in Table: ${ }^{*}$ - statistically significant effect, $n s-$ no statistically significant effect

Tablica 3. Analiza varijance ( $F$ vrijednosti) prinosa i sastavnica prinosa sjemena sorata predivog lana $u$ 2009. godini na lokaciji Zagreb

Table 3 Analysis of variance (F-values) for yield and yield components of fibre flax varieties in 2009 at location Zagreb

\begin{tabular}{|c|c|c|c|c|c|}
\hline $\begin{array}{c}\text { Izvori } \\
\text { varijabilnosti }\end{array}$ & $\begin{array}{c}\text { Broj } \\
\text { biljaka }\end{array}$ & $\begin{array}{c}\text { Prinos } \\
\text { sjemena }\end{array}$ & $\begin{array}{c}\text { Broj tobolaca } \\
\text { po biljci }\end{array}$ & $\begin{array}{l}\text { Broj sjemenki u } \\
\text { tobolcu }\end{array}$ & $\begin{array}{l}\text { Masa } 1000 \\
\text { sjemenki }\end{array}$ \\
\hline $\begin{array}{l}\text { Source of } \\
\text { variations }\end{array}$ & $\begin{array}{l}\text { Number } \\
\text { of plants }\end{array}$ & $\begin{array}{l}\text { Seed } \\
\text { yield }\end{array}$ & $\begin{array}{c}\text { Number of } \\
\text { capsules per plant }\end{array}$ & $\begin{array}{c}\text { Number of seed } \\
\text { per capsules }\end{array}$ & $\begin{array}{l}1000 \text { seed } \\
\text { weight }\end{array}$ \\
\hline \multicolumn{6}{|l|}{ Sorta (S) } \\
\hline Variety & $12,35^{*}$ & $48,45^{*}$ & $2,55^{*}$ & $5,92 *$ & $6,41 *$ \\
\hline $\begin{array}{l}\text { Gnojidba } \\
\text { dušikom } \\
\text { (GD) } \\
\text { Nitrogen } \\
\text { fertilization }\end{array}$ & $0,28 \mathrm{~ns}$ & $34,51 *$ & $5,82 *$ & $9,38 *$ & $1,44 \mathrm{~ns}$ \\
\hline $\begin{array}{l}\text { Interakcija } \\
\text { (SxGD) } \\
\text { Interaction }\end{array}$ & $0,44 \mathrm{~ns}$ & $0,48 \mathrm{~ns}$ & $0,92 \mathrm{~ns}$ & $1,27 \mathrm{~ns}$ & $0,49 \mathrm{~ns}$ \\
\hline
\end{tabular}

Oznake u tablici: ${ }^{*}$ - statistička opravdanost, ns - nema statističke opravdanosti

Designation used in Table: ${ }^{*}$ - statistically significant effect, $n s-$ no statistically significant effect 
Tablica 4. Analiza varijance (F vrijednosti) prinosa i sastavnica prinosa sjemena sorata predivog lana $u$ 2009. godini na lokaciji Križevci

Table 4 Analysis of variance ( $F$-values) for yield and yield components of fibre flax varieties in 2009 at location Križevci

\begin{tabular}{|c|c|c|c|c|c|}
\hline $\begin{array}{c}\text { Izvori } \\
\text { varijabilnosti }\end{array}$ & $\begin{array}{c}\text { Broj } \\
\text { biljaka }\end{array}$ & $\begin{array}{l}\text { Prinos } \\
\text { sjemena }\end{array}$ & $\begin{array}{l}\text { Broj tobolaca } \\
\text { po biljci }\end{array}$ & $\begin{array}{c}\text { Broj sjemenki u } \\
\text { tobolcu }\end{array}$ & $\begin{array}{c}\text { Masa } 1000 \\
\text { sjemenki }\end{array}$ \\
\hline $\begin{array}{l}\text { Source of } \\
\text { variations }\end{array}$ & $\begin{array}{l}\text { Number } \\
\text { of plants }\end{array}$ & $\begin{array}{l}\text { Seed } \\
\text { yield }\end{array}$ & $\begin{array}{c}\text { Number of } \\
\text { capsules per plant }\end{array}$ & $\begin{array}{c}\text { Number of seed } \\
\text { per capsules }\end{array}$ & $\begin{array}{l}1000 \text { seed } \\
\text { weight }\end{array}$ \\
\hline $\begin{array}{l}\text { Sorta }(\mathrm{S}) \\
\text { Variety }\end{array}$ & $2,20 \mathrm{~ns}$ & $74,34 *$ & $5,15^{*}$ & $2,18 *$ & $64,57^{*}$ \\
\hline $\begin{array}{l}\text { Gnojidba } \\
\text { dušikom (GD) } \\
\text { Nitrogen } \\
\text { fertilization }\end{array}$ & $0,75 \mathrm{~ns}$ & $42,02 *$ & $14,89 *$ & $12,55^{*}$ & $13,32 *$ \\
\hline $\begin{array}{l}\text { Interakcija } \\
\text { (SxGD) } \\
\text { Interaction }\end{array}$ & $0,89 \mathrm{~ns}$ & $0,64 \mathrm{~ns}$ & $0,77 \mathrm{~ns}$ & $1,54 \mathrm{~ns}$ & $1,22 \mathrm{~ns}$ \\
\hline
\end{tabular}

Oznake u tablici: ${ }^{*}$ - statistička opravdanost, ns - nema statističke opravdanosti

Designation used in Table: ${ }^{*}$ - statistically significant effect, $n s-$ no statistically significant effect

Tijekom 2010. godine nisu bile prisutne signifikantne razlike između sorata za broj biljaka na obje lokacije, te za broj tobolaca po biljci, broj sjemenki u tobolcu i masu 1000 sjemenki u Zagrebu i između različitih gnojidbi dušikom za broj biljaka, broj tobolaca po biljci i masu 1000 sjemenki na obje lokacije, te za prinos sjemena i broj sjemenki u tobolcu za Križevce (Tablica 5., Tablica 6.).

Tablica 5. Analiza varijance (F vrijednosti) prinosa i sastavnica prinosa sjemena sorata predivog lana u 2010. godini na lokaciji Zagreb

Table 5 Analysis of variance (F-values) for yield and yield components of fibre flax varieties in 2010 at location Zagreb

\begin{tabular}{|c|c|c|c|c|c|}
\hline $\begin{array}{c}\text { Izvori } \\
\text { varijabilnosti }\end{array}$ & $\begin{array}{c}\text { Broj } \\
\text { biljaka }\end{array}$ & $\begin{array}{c}\text { Prinos } \\
\text { sjemena }\end{array}$ & $\begin{array}{l}\text { Broj tobolaca } \\
\text { po biljci }\end{array}$ & $\begin{array}{l}\text { Broj sjemenki u } \\
\text { tobolcu }\end{array}$ & $\begin{array}{l}\text { Masa } 1000 \\
\text { sjemenki }\end{array}$ \\
\hline $\begin{array}{l}\text { Source of } \\
\text { variations }\end{array}$ & $\begin{array}{l}\text { Number } \\
\text { of plants }\end{array}$ & $\begin{array}{l}\text { Seed } \\
\text { yield }\end{array}$ & $\begin{array}{c}\text { Number of } \\
\text { capsules per plant }\end{array}$ & $\begin{array}{c}\text { Number of seed } \\
\text { per capsules }\end{array}$ & $\begin{array}{l}1000 \text { seed } \\
\text { weight }\end{array}$ \\
\hline $\begin{array}{l}\text { Sorta }(\mathrm{S}) \\
\text { Variety }\end{array}$ & $2,40 \mathrm{~ns}$ & $46,00 *$ & $0,83 \mathrm{~ns}$ & $1,57 \mathrm{~ns}$ & $1,68 \mathrm{~ns}$ \\
\hline $\begin{array}{l}\text { Gnojidba } \\
\text { dušikom (GD) } \\
\text { Nitrogen } \\
\text { fertilization }\end{array}$ & $0,98 \mathrm{~ns}$ & $41,40 *$ & $4,93 \mathrm{~ns}$ & $10,42 *$ & $1,92 \mathrm{~ns}$ \\
\hline $\begin{array}{l}\text { Interakcija } \\
\text { (SxGD) } \\
\text { Interaction }\end{array}$ & $0,55 \mathrm{~ns}$ & $0,94 \mathrm{~ns}$ & $0,58 \mathrm{~ns}$ & $1,11 \mathrm{~ns}$ & $0,05 \mathrm{~ns}$ \\
\hline
\end{tabular}

Oznake u tablici: ${ }^{*}$ - statistička opravdanost, ns - nema statističke opravdanosti

Designation used in Table: ${ }^{*}$ - statistically significant effect, $n s-$ no statistically significant effect 
Tablica 6. Analiza varijance ( $F$ vrijednosti) prinosa i sastavnica prinosa sjemena sorata predivog lana $u$ 2010. godini na lokaciji Križevci

Table 6 Analysis of variance (F-values) for yield and yield components of fibre flax varieties in 2010 at location Križevci

\begin{tabular}{|c|c|c|c|c|c|}
\hline $\begin{array}{c}\text { Izvori } \\
\text { varijabilnosti }\end{array}$ & $\begin{array}{c}\text { Broj } \\
\text { biljaka }\end{array}$ & $\begin{array}{l}\text { Prinos } \\
\text { sjemena }\end{array}$ & $\begin{array}{l}\text { Broj tobolaca } \\
\text { po biljci }\end{array}$ & $\begin{array}{c}\text { Broj sjemenki u } \\
\text { tobolcu }\end{array}$ & $\begin{array}{l}\text { Masa } 1000 \\
\text { sjemenki }\end{array}$ \\
\hline $\begin{array}{l}\text { Source of } \\
\text { variations }\end{array}$ & $\begin{array}{l}\text { Number } \\
\text { of plants }\end{array}$ & $\begin{array}{l}\text { Seed } \\
\text { yield }\end{array}$ & $\begin{array}{c}\text { Number of } \\
\text { capsules per plant }\end{array}$ & $\begin{array}{c}\text { Number of seed per } \\
\text { capsules }\end{array}$ & $\begin{array}{c}1000 \text { seed } \\
\text { weight }\end{array}$ \\
\hline $\begin{array}{l}\text { Sorta }(\mathrm{S}) \\
\text { Variety }\end{array}$ & $1,79 \mathrm{~ns}$ & $8,21 *$ & $13,80^{*}$ & $23,91 *$ & $7,39 *$ \\
\hline $\begin{array}{l}\text { Gnojidba } \\
\text { dušikom (GD) } \\
\text { Nitrogen } \\
\text { fertilization }\end{array}$ & $2,42 \mathrm{~ns}$ & $2,05 \mathrm{~ns}$ & $1,57 \mathrm{~ns}$ & $2,48 \mathrm{~ns}$ & $2,23 \mathrm{~ns}$ \\
\hline $\begin{array}{l}\text { Interakcija } \\
\text { (SxGD) } \\
\text { Interaction }\end{array}$ & $0,86 \mathrm{~ns}$ & $0,29 \mathrm{~ns}$ & $1,46 \mathrm{~ns}$ & $1,59 \mathrm{~ns}$ & $0,89 \mathrm{~ns}$ \\
\hline
\end{tabular}

Oznake u tablici: ${ }^{*}$ - statistička opravdanost, ns - nema statističke opravdanosti

Designation used in Table: ${ }^{*}$ - statistically significant effect, $n s-$ no statistically significant effect

Interakcija (sorta $\mathrm{x}$ gnojidba dušikom) nije bila signifikantna ni za jedno istraživano svojstvo u sve tri godine istraživanja.

Signifikantno najveći broj biljaka ostvarile su sorte Viking i Agatha tijekom 2008. godine na obje lokacije (Tablica 7., Tablica 8.).

Tablica 7. Prosječne vrijednosti prinosa i sastavnica prinosa sjemena sorata predivog lana u 2008. godini na lokaciji Zagreb

Table 7 Means of yield and yield components of fibre flax varieties in 2008 at location Zagreb

\begin{tabular}{cccccc}
\hline Sorta & $\begin{array}{c}\text { Broj } \\
\text { biljaka }\left(\mathrm{m}^{2}\right)\end{array}$ & $\begin{array}{c}\text { Prinos sjemena } \\
\left(\mathrm{t} \mathrm{ha}^{-1}\right)\end{array}$ & $\begin{array}{c}\text { Broj tobolaca } \\
\text { po biljci }\end{array}$ & $\begin{array}{c}\text { Broj sjemenki u } \\
\text { tobolcu }\end{array}$ & $\begin{array}{c}\text { Masa } 1000 \\
\text { sjemenki }(\mathrm{g})\end{array}$ \\
$\begin{array}{c}\text { Number of } \\
\text { plants }\left(\mathrm{m}^{2}\right)\end{array}$ & $\begin{array}{c}\text { Number of } \\
\left(t \text { h } \mathrm{a}^{-1}\right)\end{array}$ & $\begin{array}{c}\text { Number of seed } \\
\text { per capsules }\end{array}$ & $\begin{array}{c}\text { 1000 seed } \\
\text { weight }(\mathrm{g})\end{array}$ \\
\hline Viking & $2200 \mathrm{a}$ & $1,20 \mathrm{a}$ & $5 \mathrm{a}$ & $9 \mathrm{a}$ & $5,36 \mathrm{a}$ \\
\hline Viola & $1755 \mathrm{~b}$ & $1,12 \mathrm{~b}$ & $4 \mathrm{~b}$ & $8 \mathrm{~b}$ & $4,70 \mathrm{a}$ \\
\hline Venica & $1871 \mathrm{~b}$ & $1,15 \mathrm{ab}$ & $5 \mathrm{a}$ & $8 \mathrm{~b}$ & $4,87 \mathrm{a}$ \\
\hline Agatha & $2171 \mathrm{a}$ & $1,00 \mathrm{c}$ & $4 \mathrm{~b}$ & $8 \mathrm{~b}$ & $4,61 \mathrm{~b}$ \\
\hline Electra & $1877 \mathrm{~b}$ & $1,12 \mathrm{~b}$ & $4 \mathrm{~b}$ & $8 \mathrm{~b}$ & $4,95 \mathrm{a}$ \\
\hline
\end{tabular}

Vrijednosti označene istim slovom nisu signifikantne na nivou od 5\%

Values having the same letter are not significant at a level of $5 \%$ 
Tablica 8. Prosječne vrijednosti prinosa i sastavnica prinosa sjemena sorata predivog lana u 2008. godini na lokaciji Križevci

Table 8 Means of yield and yield components of fibre flax varieties in 2008 at location Križevci

\begin{tabular}{|c|c|c|c|c|c|}
\hline $\begin{array}{l}\text { Sorta } \\
\text { Variety }\end{array}$ & $\begin{array}{l}\text { Broj biljaka } \\
\left(\mathrm{m}^{2}\right) \\
\text { Number of } \\
\text { plants }\left(\mathrm{m}^{2}\right)\end{array}$ & $\begin{array}{l}\text { Prinos sjemena } \\
\left(\mathrm{t} \mathrm{ha}^{-1}\right) \\
\text { Seed yield } \\
\left(t \mathrm{ha}^{-1}\right)\end{array}$ & $\begin{array}{l}\text { Broj tobolaca } \\
\text { po biljci } \\
\text { Number of capsules } \\
\text { per plant }\end{array}$ & $\begin{array}{l}\text { Broj sjemenki u } \\
\text { tobolcu } \\
\text { Number of seed } \\
\text { per capsules }\end{array}$ & $\begin{array}{l}\text { Masa } 1000 \\
\text { sjemenki }(\mathrm{g}) \\
\text { 1000 seed } \\
\text { weight }(\mathrm{g})\end{array}$ \\
\hline Viking & $1963 \mathrm{a}$ & $1,31 \mathrm{a}$ & $5 \mathrm{a}$ & $6 a$ & $6,08 \mathrm{a}$ \\
\hline Viola & $1820 \mathrm{~b}$ & $1,12 \mathrm{c}$ & $4 b$ & $6 a$ & $5,95 \mathrm{a}$ \\
\hline Venica & $1813 b$ & $1,21 \mathrm{~b}$ & $4 b$ & $6 a$ & $6,16 \mathrm{a}$ \\
\hline Agatha & $1965 \mathrm{a}$ & $1,10 \mathrm{c}$ & $4 b$ & $6 a$ & $5,77 \mathrm{a}$ \\
\hline Electra & $1815 b$ & $1,23 \mathrm{~b}$ & $4 b$ & $6 a$ & $6,30 \mathrm{a}$ \\
\hline
\end{tabular}

Vrijednosti označene istim slovom nisu signifikantne na nivou od 5\%

Values having the same letter are not significant at a level of $5 \%$

Sorta Viking je i tijekom 2009. godine imala najveći sklop (Tablica 9., Tablica 10.), dok je tijekom 2010. bila druga po ostvarenom sklopu (Tablica 11., Tablica 12.). Sve istraživane sorte tijekom trogodišnjih istraživanja ostvarile su preporučljiv sklop u berbi lana koji je bio viši od 1.750 biljaka $/ \mathrm{m}^{2}$.

Tablica 9. Prosječne vrijednosti prinosa i sastavnica prinosa sjemena sorata predivog lana u 2009. godini na lokaciji Zagreb

Table 9 Means of yield and yield components of fibre flax varieties in 2009 at location Zagreb

\begin{tabular}{lccccc}
\hline $\begin{array}{c}\text { Sorta } \\
\text { Variety }\end{array}$ & $\begin{array}{c}\text { Broj biljaka } \\
\left(\mathrm{m}^{2}\right) \\
\text { Number } \\
\text { of plants }\left(\mathrm{m}^{2}\right)\end{array}$ & $\begin{array}{c}\text { Prinos sjemena } \\
\left(\mathrm{t} \mathrm{ha}^{-1}\right) \\
\text { Seed yield } \\
\left(t \text { ha }{ }^{-1}\right)\end{array}$ & $\begin{array}{c}\text { Broj tobolaca } \\
\text { po biljci } \\
\text { Number of } \\
\text { capsules per plant }\end{array}$ & $\begin{array}{c}\text { Broj sjemenki u } \\
\text { tobolcu } \\
\text { Number of seed } \\
\text { per capsules }\end{array}$ & $\begin{array}{c}\text { Masa } 1000 \\
\text { sjemenki }(\mathrm{g}) \\
1000 \text { seed } \\
\text { weight }(\mathrm{g})\end{array}$ \\
\hline Viking & $2185 \mathrm{a}$ & $0,91 \mathrm{a}$ & $4 \mathrm{a}$ & $5 \mathrm{a}$ & $3,68 \mathrm{~b}$ \\
\hline Viola & $2048 \mathrm{~b}$ & $0,80 \mathrm{~b}$ & $4 \mathrm{a}$ & $5 \mathrm{a}$ & $3,16 \mathrm{ab}$ \\
\hline Venica & $2104 \mathrm{ab}$ & $0,86 \mathrm{ab}$ & $4 \mathrm{a}$ & $5 \mathrm{a}$ & $3,70 \mathrm{a}$ \\
\hline Agatha & $2133 \mathrm{ab}$ & $0,70 \mathrm{c}$ & $3 \mathrm{~b}$ & $4 \mathrm{~b}$ & $3,37 \mathrm{ab}$ \\
\hline Electra & $2116 \mathrm{ab}$ & $0,83 \mathrm{~b}$ & $3 \mathrm{~b}$ & $5 \mathrm{a}$ & $3,21 \mathrm{ab}$ \\
\hline
\end{tabular}

Vrijednosti označene istim slovom nisu signifikantne na nivou od 5\%

Values having the same letter are not significant at a level of $5 \%$ 
Tablica 10. Prosječne vrijednosti prinosa i sastavnica prinosa sjemena sorata predivog lana u 2009. godini na lokaciji Križevci

Table 10 Means of yield and yield components of fibre flax varieties in 2009. at location Križevci

\begin{tabular}{|c|c|c|c|c|c|}
\hline $\begin{array}{c}\text { Sorta } \\
\text { Variety }\end{array}$ & 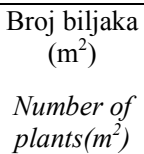 & $\begin{array}{c}\text { Prinos sjemena } \\
\left(\mathrm{t} \mathrm{ha}^{-1}\right) \\
\text { Seed yield } \\
\left(t \mathrm{ha}^{-1}\right)\end{array}$ & $\begin{array}{c}\text { Broj tobolaca } \\
\text { po biljci } \\
\text { Number of } \\
\text { capsules per plant }\end{array}$ & $\begin{array}{c}\text { Broj sjemenki u } \\
\text { tobolcu } \\
\text { Number of seed } \\
\text { per capsules }\end{array}$ & $\begin{array}{c}\text { Masa } 1000 \\
\text { sjemenki }(\mathrm{g}) \\
1000 \text { seed } \\
\text { weight }(\mathrm{g})\end{array}$ \\
\hline Viking & $2011 \mathrm{a}$ & $1,41 \mathrm{a}$ & $10 \mathrm{a}$ & $7 \mathrm{a}$ & $5,71 \mathrm{a}$ \\
\hline Viola & $2017 \mathrm{a}$ & $1,20 \mathrm{c}$ & $9 b$ & $6 \mathrm{~b}$ & $5,20 \mathrm{a}$ \\
\hline Venica & $1957 \mathrm{a}$ & $1,31 \mathrm{~b}$ & $10 \mathrm{a}$ & $6 \mathrm{~b}$ & $5,56 \mathrm{a}$ \\
\hline Agatha & $1981 \mathrm{a}$ & $1,21 \mathrm{c}$ & $9 b$ & $6 \mathrm{~b}$ & $5,31 b$ \\
\hline Electra & $1968 \mathrm{a}$ & $1,31 b$ & $9 b$ & $6 b$ & $5,71 \mathrm{a}$ \\
\hline
\end{tabular}

Vrijednosti označene istim slovom nisu signifikantne na nivou od 5\%

Values having the same letter are not significant at a level of $5 \%$

Tablica 11. Prosječne vrijednosti prinosa i sastavnica prinosa sjemena sorata predivog lana u 2010. godini na lokaciji Zagreb

Table 11 Means of yield and yield components of fibre flax varieties in 2010 at location Zagreb

\begin{tabular}{llcccc}
\hline Sorta & $\begin{array}{c}\text { Broj biljaka } \\
\left(\mathrm{m}^{2}\right) \\
\text { Vumber of } \\
\text { plants }\left(\mathrm{m}^{2}\right)\end{array}$ & $\begin{array}{c}\text { Prinos sjemena } \\
\left(\mathrm{t} \mathrm{ha}^{-1}\right) \\
\text { Seed yield } \\
\left(\mathrm{t} \mathrm{ha}^{-1}\right)\end{array}$ & $\begin{array}{c}\text { Broj tobolaca } \\
\text { po biljci } \\
\text { Number of } \\
\text { capsules per plant }\end{array}$ & $\begin{array}{c}\text { Broj sjemenki u } \\
\text { tobolcu } \\
\text { Number of seed } \\
\text { per capsules }\end{array}$ & $\begin{array}{c}\text { Masa 1000 } \\
\text { sjemenki }(\mathrm{g}) \\
1000 \text { seed } \\
\text { weight }(\mathrm{g})\end{array}$ \\
\hline Viking & Viking & $1954 \mathrm{a}$ & $1,13 \mathrm{a}$ & $7 \mathrm{a}$ & $7 \mathrm{a}$ \\
\hline Viola & Viola & $1791 \mathrm{a}$ & $0,93 \mathrm{~b}$ & $6 \mathrm{a}$ & $6 \mathrm{a}$ \\
\hline Venica & Venica & $1912 \mathrm{a}$ & $1,05 \mathrm{a}$ & $7 \mathrm{a}$ & $7 \mathrm{a}$ \\
\hline Agatha & Agatha & $1930 \mathrm{a}$ & $0,91 \mathrm{~b}$ & $6 \mathrm{a}$ & $6 \mathrm{a}$ \\
\hline Electra & Electra & $2023 \mathrm{a}$ & $0,96 \mathrm{~b}$ & $6 \mathrm{a}$ & $6 \mathrm{a}$ \\
\hline
\end{tabular}

Vrijednosti označene istim slovom nisu signifikantne na nivou od 5\%

Values having the same letter are not significant at a level of 5\% 
Jasminka Butorac i sur.: Utjecaj gnojidbe dušikom na prinos

i sastavnice prinosa sjemena nekih sorata predivog lana

Tablica 12. Prosječne vrijednosti prinosa i sastavnica prinosa sjemena sorata predivog lana u 2010. godini na lokaciji Križevci

Table 12 Means of yield and yield components of fibre flax varieties in 2010 at location Križevci

\begin{tabular}{|c|c|c|c|c|c|}
\hline $\begin{array}{c}\text { Sorta } \\
\text { Variety }\end{array}$ & 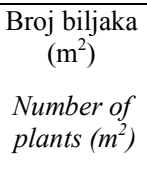 & $\begin{array}{c}\text { Prinos sjemena } \\
\left(\mathrm{t} \mathrm{ha}^{-1}\right) \\
\text { Seed yield } \\
\left(t h a^{-1}\right)\end{array}$ & $\begin{array}{c}\text { Broj tobolaca } \\
\text { po biljci } \\
\text { Number of capsules } \\
\text { per plant }\end{array}$ & $\begin{array}{l}\text { Broj sjemenki } \\
\mathrm{u} \text { tobolcu } \\
\text { Number of } \\
\text { seed per } \\
\text { capsules }\end{array}$ & $\begin{array}{c}\text { Masa } 1000 \\
\text { sjemenki }(\mathrm{g}) \\
1000 \text { seed } \\
\text { weight }(\mathrm{g})\end{array}$ \\
\hline Viking & $2024 a$ & $1,30 \mathrm{a}$ & $7 b$ & $6 b$ & $5,73 a$ \\
\hline Viola & $2159 a$ & $1,12 b$ & $6 c$ & $6 \mathrm{~b}$ & $5,24 b$ \\
\hline Venica & $1961 \mathrm{a}$ & $1,28 \mathrm{a}$ & $8 \mathrm{a}$ & $7 \mathrm{a}$ & $5,69 \mathrm{a}$ \\
\hline Agatha & $2006 a$ & $1,11 b$ & $7 b$ & $5 c$ & $5,29 \mathrm{a}$ \\
\hline Electra & $2023 a$ & $1,25 \mathrm{a}$ & $7 b$ & $6 b$ & $5,51 \mathrm{a}$ \\
\hline
\end{tabular}

Vrijednosti označene istim slovom nisu signifikantne na nivou od 5\%

Values having the same letter are not significant at a level of 5\%

Signifikantno najveći prinos sjemena predivog lana ostvarila je sorta Viking u 2008. i 2009. godini u Križevcima. U 2008., 2009. i 2010. godini nije bilo sigifikantnih razlika u prinosu sjemena između sorata Viking i Venica u Zagrebu, te u 2010. između sorata Viking, Venica i Electra u Križevcima. Ostale sorte imale su signifikantno manji prinos sjemena. Drugi najveći prosječni prinos sjemena u tri godine u Zagrebu i dvije u Križevcima ostvarila je sorta Venica. Najmanji prinos sjemena ostvarila je u trogodišnjim istraživanjima sorta Agatha.

Ako se pogledaju rezultati dobivenog prinosa sjemena može se reći da su prisutne razlike u ostvarenim prinosima između godina istraživanja i lokacija. Najveći prosječni prinosi sjemena s obzirom na godinu istraživanja ostvareni su tijekom 2008. godine u Zagrebu i tijekom 2009. godine u Križevcima. U sve tri godine istraživanja veći prosječni prinosi sjemena ostvareni su u Križevcima. Prosječni prinosi sjemena trebali bi se kretati između 1,3 i $1,5 \mathrm{t} \mathrm{ha}^{-1}$ (D a enekindt 2003. i Pavelek, 2001.) Dobivene vrijednosti niže su od navedenih, pogotovo u Zagrebu, ili su u skladu sa istraživanjima koja su već provedena ranije u Hrvatskoj (Butorac i sur., 2006b i 2010a). Niži prinosi sjemena $u$ našim istraživanjima posljedica su izrazito visokih temperatura $u$ vrijeme formiranja i sazrijevanja sjemena (tijekom lipnja i srpnja apsolutne maksimalne temperature bile su više od $32^{\circ} \mathrm{C}$ ). Razlike u prinosima sjemena između lokacija mogu se pripisati tipu tla, tj. uzgoju predivog lana u Zagrebu na pjeskovitijem tlu. Tijekom proljetnih mjeseci, pogotovo u 2009. i 2010. godini javio se nedostatak vode u površinskom sloju tla.

Ako pogledamo rezultate ostvarenih sastavnica prinosa sjemena možemo reći da su sorte Viking i Venica ostvarile i najveće vrijednosti broja tobolaca po biljci, broja sjemenki u tobolcu, te mase 1000 sjemenki u trogodišnjim istraživanjima. Prema 
dosadašnjim istraživanjima u Hrvatskoj na jednoj biljci lana obično ima 8 do 10 tobolaca, u tobolcu 6 do 8 sjemenki, a masa 1000 sjemenki iznosi 3 do $6,5 \mathrm{~g}$. (Butorac i sur., 2006b i 2010a). Niže dobivene vrijednosti u našim istraživanjima, pogotovo u Zagrebu, za broj tobolaca po biljci posljedica su nepovoljnih vremenskih prilika u vrijeme cvatnje.

Ako se usporede dobivene vrijednosti istraživanja s obzirom na gnojidbu dušikom, vidljivo je da su prihranjeni usjevi ostvarili više vrijednosti od usjeva koji nisu bili prihranjivani tijekom vegetacije (Tablica13., Tablica 14.).

Tablica 13. Prosječne vrijednosti prinosa i sastavnica prinosa sjemena predivog lana pri različitoj gnojidbi dušikom u 2008. godini na lokaciji Zagreb

Table 13 Means of yield and yield components of fibre flax with different nitrogen rates in 2008 at location Zagreb

\begin{tabular}{|c|c|c|c|c|c|}
\hline $\begin{array}{c}\text { Gnojidba } \\
\text { dušikom } \\
\left(\mathrm{kg} \mathrm{ha}^{-1}\right) \\
\text { Nitrogen } \\
\text { fertilization } \\
\left(\mathrm{kg} \mathrm{ha}^{-1}\right)\end{array}$ & 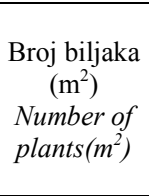 & $\begin{array}{l}\text { Prinos sjemena } \\
\left(\mathrm{t} \mathrm{ha}^{-1}\right) \\
\text { Seed yield } \\
\left(t h a^{-1}\right)\end{array}$ & $\begin{array}{c}\text { Broj tobolaca } \\
\text { po biljci } \\
\text { Number of } \\
\text { capsules per plant }\end{array}$ & $\begin{array}{c}\text { Broj sjemenki u } \\
\text { tobolcu } \\
\text { Number of seed } \\
\text { per capsules }\end{array}$ & $\begin{array}{c}\text { Masa } 1000 \\
\text { sjemenki (g) } \\
1000 \text { seed } \\
\text { weight }(\mathrm{g})\end{array}$ \\
\hline 0 & $1962 a$ & $1,07 b$ & $4 b$ & $7 b$ & $4,47 b$ \\
\hline 30 & $1965 a$ & $1,17 \mathrm{a}$ & $5 \mathrm{a}$ & $8 \mathrm{a}$ & $5,09 \mathrm{a}$ \\
\hline 60 & $1977 \mathrm{a}$ & $1,18 \mathrm{a}$ & $5 \mathrm{a}$ & $8 \mathrm{a}$ & $5,21 \mathrm{a}$ \\
\hline 90 & $1996 a$ & $1,06 b$ & $4 \mathrm{~b}$ & $7 b$ & $5,83 a$ \\
\hline
\end{tabular}

Vrijednosti označene istim slovom nisu signifikantne na nivou od 5\%

Values having the same letter are not significant at a level of $5 \%$

Tablica 14. Prosječne vrijednosti prinosa i sastavnica prinosa sjemena predivog lana pri različitoj gnojidbi dušikom u 2008. godini na lokaciji Križevci

Table 14 Means of yield and yield components of fibre flax with different nitrogen rates in 2008 at location Križevci

\begin{tabular}{|c|c|c|c|c|c|}
\hline $\begin{array}{l}\text { Gnojidba } \\
\text { dušikom } \\
\left(\mathrm{kg} \mathrm{ha}^{-1}\right) \\
\text { Nitrogen } \\
\text { fertilization } \\
\left(\mathrm{kg} \mathrm{ha}^{-1}\right)\end{array}$ & 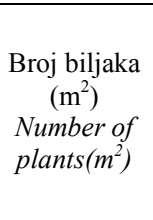 & $\begin{array}{l}\text { Prinos } \\
\text { sjemena } \\
\left(\mathrm{t} \mathrm{ha}^{-1}\right) \\
\text { Seed yield } \\
\left(t \mathrm{ha}^{-1}\right)\end{array}$ & $\begin{array}{l}\text { Broj tobolaca } \\
\text { po biljci } \\
\text { Number of } \\
\text { capsules } \\
\text { per plant }\end{array}$ & $\begin{array}{c}\text { Broj sjemenki u } \\
\text { tobolcu } \\
\text { Number of seed per } \\
\text { capsules }\end{array}$ & $\begin{array}{l}\text { Masa } 1000 \\
\text { sjemenki } \\
(\mathrm{g}) \\
1000 \text { seed } \\
\text { weight }(\mathrm{g})\end{array}$ \\
\hline 0 & $1958 \mathrm{a}$ & $1,14 \mathrm{~b}$ & $3 b$ & $5 b$ & $5,69 b$ \\
\hline 30 & $1960 \mathrm{a}$ & $1,24 \mathrm{a}$ & $4 a$ & $6 a$ & $6,24 a$ \\
\hline 60 & 1971a & $1,25 \mathrm{a}$ & $4 a$ & $6 a$ & $6,33 a$ \\
\hline 90 & 1986a & $1,15 b$ & $4 a$ & $6 a$ & $5,95 \mathrm{a}$ \\
\hline
\end{tabular}

Vrijednosti označene istim slovom nisu signifikantne na nivou od 5\%

Values having the same letter are not significant at a level of $5 \%$ 
Signifikantno najmanje vrijednosti za većinu istraživanih svojstava dobivene su u varijante koja nije gnojena dušikom (Tablica 15., Tablica 16.).

Tablica 15. Prosječne vrijednosti prinosa i sastavnica prinosa sjemena predivog lana pri različitoj gnojidbi dušikom u 2009. godini na lokaciji Zagreb

Table 15 Means of yield and yield components of fibre flax with different nitrogen rates in 2009 at location Zagreb

\begin{tabular}{|c|c|c|c|c|c|}
\hline $\begin{array}{l}\text { Gnojidba } \\
\text { dušikom } \\
\left(\mathrm{kg} \mathrm{ha}^{-1}\right)\end{array}$ & $\begin{array}{l}\text { Broj biljaka } \\
\left(\mathrm{m}^{2}\right)\end{array}$ & $\begin{array}{l}\text { Prinos sjemena } \\
\left(\mathrm{t} \mathrm{ha}^{-1}\right)\end{array}$ & $\begin{array}{l}\text { Broj tobolaca } \\
\text { po biljci }\end{array}$ & $\begin{array}{l}\text { Broj sjemenki u } \\
\text { tobolcu }\end{array}$ & $\begin{array}{c}\text { Masa } 1000 \\
\text { sjemenki }(\mathrm{g})\end{array}$ \\
\hline $\begin{array}{c}\text { Nitrogen } \\
\text { fertilization } \\
\left(\mathrm{kg} \mathrm{ha}^{-1}\right)\end{array}$ & $\begin{array}{c}\text { Number } \\
\text { of plants }\left(m^{2}\right)\end{array}$ & $\begin{array}{l}\text { Seed yield } \\
\quad\left(t h a^{-1}\right)\end{array}$ & $\begin{array}{c}\text { Number of } \\
\text { capsules } \\
\text { per plant }\end{array}$ & $\begin{array}{c}\text { Number of seed } \\
\text { per capsules }\end{array}$ & $\begin{array}{l}1000 \text { seed } \\
\text { weight }(g)\end{array}$ \\
\hline 0 & $2118 \mathrm{a}$ & $0,77 \mathrm{~b}$ & $3 b$ & $4 b$ & $3,15 \mathrm{a}$ \\
\hline 30 & $2123 a$ & $0,86 \mathrm{a}$ & $4 a$ & $5 \mathrm{a}$ & $3,43 \mathrm{a}$ \\
\hline 60 & $2121 \mathrm{a}$ & $0,88 \mathrm{a}$ & $4 a$ & $5 a$ & $3,58 \mathrm{a}$ \\
\hline 90 & $2108 \mathrm{a}$ & $0,77 b$ & $4 a$ & $5 a$ & $3,52 \mathrm{a}$ \\
\hline
\end{tabular}

Vrijednosti označene istim slovom nisu signifikantne na nivou od 5\%

Values having the same letter are not significant at a level of $5 \%$

Tablica 16. Prosječne vrijednosti prinosa i sastavnica prinosa sjemena predivog lana pri različitoj gnojidbi dušikom u 2009. godini na lokaciji Križevci

Table 16 Means of yield and yield components of fibre flax with different nitrogen rates in 2009 at location Križevci

\begin{tabular}{|c|c|c|c|c|c|}
\hline $\begin{array}{l}\text { Gnojidba } \\
\text { dušikom } \\
\left(\mathrm{kg} \mathrm{ha}^{-1}\right)\end{array}$ & $\begin{array}{c}\text { Broj biljaka } \\
\left(\mathrm{m}^{2}\right)\end{array}$ & $\begin{array}{l}\text { Prinos } \\
\text { sjemena } \\
\left(\mathrm{t} \mathrm{ha}^{-1}\right)\end{array}$ & $\begin{array}{c}\text { Broj tobolaca } \\
\text { po biljci }\end{array}$ & $\begin{array}{c}\text { Broj sjemenki u } \\
\text { tobolcu }\end{array}$ & $\begin{array}{c}\text { Masa } 1000 \\
\text { sjemenki (g) }\end{array}$ \\
\hline $\begin{array}{c}\text { Nitrogen } \\
\text { fertilization } \\
\left(\mathrm{kg} \mathrm{ha} \mathrm{a}^{-1}\right)\end{array}$ & $\begin{array}{l}\text { Number of } \\
\text { plants }\left(m^{2}\right)\end{array}$ & $\begin{array}{l}\text { Seed yield } \\
\quad\left(t h a^{-1}\right)\end{array}$ & $\begin{array}{c}\text { Number of } \\
\text { capsules } \\
\text { per plant }\end{array}$ & $\begin{array}{c}\text { Number of seed } \\
\text { per capsules }\end{array}$ & $\begin{array}{l}1000 \text { seed } \\
\text { weight }(g)\end{array}$ \\
\hline 0 & $1984 \mathrm{a}$ & $1,24 b$ & $9 b$ & $6 b$ & $5,39 b$ \\
\hline 30 & $1986 a$ & $1,34 \mathrm{a}$ & $9 b$ & $7 a$ & $5,56 \mathrm{ab}$ \\
\hline 60 & 1999a & $1,34 \mathrm{a}$ & $10 \mathrm{a}$ & $7 a$ & $5,60 \mathrm{a}$ \\
\hline 90 & $1969 a$ & $1,24 b$ & $10 \mathrm{a}$ & $7 a$ & $5,46 a b$ \\
\hline
\end{tabular}

Vrijednosti označene istim slovom nisu signifikantne na nivou od 5\%

Values having the same letter are not significant at a level of $5 \%$ 
Prema dobivenim vrijednostima istraživanih svojstava nije bilo signifikantnih razlika između varijanata u kojima je dodano 30 i $60 \mathrm{~kg} \mathrm{ha}^{-1}$ dušika. Najveće vrijednosti ostvarene su pri gnojidbi od $60 \mathrm{~kg} \mathrm{ha}^{-1}$ dušika. Prisutne su i razlike između godina istraživanja i lokacija. S obzirom na lokaciju, veće vrijednosti istraživanih svojstava dobivene su u Križevcima (Tablica 17., Tablica 18.).

Tablica 17. Prosječne vrijednosti prinosa i sastavnica prinosa sjemena predivog lana pri različitoj gnojidbi dušikom u 2010. godini na lokaciji Zagreb

Table 17 Means of yield and yield components of fibre flax with different nitrogen rates in 2010 at location Zagreb

\begin{tabular}{|c|c|c|c|c|c|}
\hline $\begin{array}{c}\text { Gnojidba } \\
\text { dušikom } \\
\left(\mathrm{kg} \mathrm{ha}^{-1}\right)\end{array}$ & $\begin{array}{l}\text { Broj biljaka } \\
\qquad\left(\mathrm{m}^{2}\right)\end{array}$ & $\begin{array}{l}\text { Prinos } \\
\text { sjemena } \\
\left(\mathrm{t} \mathrm{ha}^{-1}\right)\end{array}$ & $\begin{array}{c}\text { Broj tobolaca } \\
\text { po biljci }\end{array}$ & $\begin{array}{c}\text { Broj sjemenki } \\
\text { u tobolcu }\end{array}$ & $\begin{array}{c}\text { Masa } 1000 \\
\text { sjemenki (g) }\end{array}$ \\
\hline $\begin{array}{c}\text { Nitrogen } \\
\text { fertilization } \\
\left(\mathrm{kg} \mathrm{ha}^{-1}\right)\end{array}$ & $\begin{array}{l}\text { Number of } \\
\text { plants }\left(m^{2}\right)\end{array}$ & $\begin{array}{l}\text { Seed yield } \\
\quad\left(t h a^{-1}\right)\end{array}$ & $\begin{array}{c}\text { Number of } \\
\text { capsules } \\
\text { per plant }\end{array}$ & $\begin{array}{c}\text { Number of seed } \\
\text { per capsules }\end{array}$ & $\begin{array}{l}1000 \text { seed } \\
\text { weight }(g)\end{array}$ \\
\hline 0 & $1922 \mathrm{a}$ & $0,91 b$ & $6 a$ & $5 b$ & $5,20 \mathrm{a}$ \\
\hline 30 & $1968 \mathrm{a}$ & $1,02 \mathrm{a}$ & $7 a$ & $7 a$ & $5,62 \mathrm{a}$ \\
\hline 60 & $1881 \mathrm{a}$ & $1,09 \mathrm{a}$ & $7 a$ & $7 \mathrm{a}$ & $5,87 \mathrm{a}$ \\
\hline 90 & $1919 a$ & $0,95 b$ & $7 a$ & $7 a$ & $5,82 \mathrm{a}$ \\
\hline
\end{tabular}

Vrijednosti označene istim slovom nisu signifikantne na nivou od 5\%

Values having the same letter are not significant at a level of $5 \%$

Tablica 18. Prosječne vrijednosti prinosa i sastavnica prinosa sjemena predivog lana pri različitoj gnojidbi dušikom u 2010. godini na lokaciji Križevci

Table 18 Means of yield and yield components of fibre flax with different nitrogen rates in 2010 at location Križevci

\begin{tabular}{|c|c|c|c|c|c|}
\hline $\begin{array}{l}\text { Gnojidba } \\
\text { dušikom } \\
\left(\mathrm{kg} \mathrm{ha}^{-1}\right)\end{array}$ & $\begin{array}{l}\text { Broj biljaka } \\
\left(\mathrm{m}^{2}\right)\end{array}$ & $\begin{array}{l}\text { Prinos } \\
\text { sjemena } \\
\left(\mathrm{t} \mathrm{ha}^{-1}\right)\end{array}$ & $\begin{array}{l}\text { Broj tobolaca } \\
\text { po biljci }\end{array}$ & $\begin{array}{l}\text { Broj sjemenki u } \\
\text { tobolcu }\end{array}$ & $\begin{array}{c}\text { Masa } 1000 \\
\text { sjemenki }(\mathrm{g})\end{array}$ \\
\hline $\begin{array}{c}\text { Nitrogen } \\
\text { fertilization } \\
\left(\mathrm{kg} \mathrm{ha}^{-1}\right)\end{array}$ & $\begin{array}{l}\text { Number of } \\
\text { plants }\left(m^{2}\right)\end{array}$ & $\begin{array}{l}\text { Seed yield } \\
\quad\left(t h a^{-1}\right)\end{array}$ & $\begin{array}{c}\text { Number of } \\
\text { capsules } \\
\text { per plant }\end{array}$ & $\begin{array}{c}\text { Number of seed per } \\
\text { capsules }\end{array}$ & $\begin{array}{l}1000 \text { seed } \\
\text { weight }(g)\end{array}$ \\
\hline 0 & $2058 \mathrm{a}$ & $1,12 \mathrm{a}$ & $7 \mathrm{a}$ & $6 a$ & $5,20 \mathrm{a}$ \\
\hline 30 & $2007 a$ & $1,22 \mathrm{a}$ & $7 a$ & $6 a$ & $5,52 \mathrm{a}$ \\
\hline 60 & $2002 a$ & $1,26 \mathrm{a}$ & $7 a$ & $6 a$ & $5,66 \mathrm{a}$ \\
\hline 90 & $1992 a$ & $1,24 \mathrm{a}$ & $7 a$ & $6 a$ & $5,57 \mathrm{a}$ \\
\hline
\end{tabular}

Vrijednosti označene istim slovom nisu signifikantne na nivou od 5\%

Values having the same letter are not significant at a level of $5 \%$ 
Jasminka Butorac i sur.: Utjecaj gnojidbe dušikom na prinos i sastavnice prinosa sjemena nekih sorata predivog lana

Rezultati dosadašnjih istraživanja gnojidbe predivog lana dušikom su različiti, ovisno o dodanim količinama dušika, vremenu primjene i vremenskim prilikama. Prema većini dosadašnjih istraživanja nema signifikantnog povećanja prinosa i sastavnica prinosa sjemena kada se dodaju veće količine dušika od $30 \mathrm{~kg} \mathrm{ha}^{-1}$ (C re mas c hi i sur., 1996., Les i sur., 1977., Zedan i sur., 1999.). Za razliku od njih, Rossini i sur. (1997.) nisu dobili povećanje prinosa sjemena lana povećanjem doza primijenjenog dušika.

\section{ZAKLJUČCI}

$\mathrm{Na}$ osnovi trogodišnjih istraživanja prinosa i sastavnica prinosa predivog lana mogu se donijeti sljedeći zaključci:

Za broj biljaka prisutne su statistički opravdane razlike između sorata u Zagrebu tijekom 2008. i 2009. godine, te za Križevce tijekom 2008. godine. Sve istraživane sorte tijekom trogodišnjih istraživanja ostvarile su preporučljiv sklop u berbi lana koji je bio viši od 1.750 biljaka $/ \mathrm{m}^{2}$. Nisu prisutne signifikantne razlike za broj biljaka između neprihranjivanih i prihranjivanih usjeva predivog lana.

Prisutne su statistički opravdane razlike u prinosu sjemena između istraživanih sorata na obje lokacije tijekom trogodišnjih istraživanja i između neprihranjivanog $i$ prihranjivanog usjeva lana, izuzev za Križevce u 2010. godini. Najveće prinose sjemena ostvarile su sorte Viking i Venica u Zagrebu i Križevcima, te Electra u Križevcima. Prema dobivenim vrijednostima istraživanih svojstava nije bilo signifikantnih razlika između varijanata u kojima je dodano 30 i $60 \mathrm{~kg} \mathrm{ha}^{-1}$ dušika.

Postoje statistički opravdane razlike između sorata za broj tobolaca po biljci, izuzev za Zagreb u 2010. godini, kao i između neprihranjivanog i prihranjivanog usjeva lana, izuzev u 2010. godini za obje lokacije. Sorte Viking i Venica imale su najveći broj tobolaca po biljci. U prihranjenom usjevu bilo je signifikantno više tobolaca na biljci lana.

Za broj sjemenki u tobolcu, prema dobivenim vrijednostima prisutne su statistički opravdane razlike između istraživanih sorata lana, izuzev za Križevce u 2008. godini i Zagreb u 2010. godini. U prihranjivanom usjevu lana bilo je signifikantno više sjemenki u tobolcu, izuzev u Križevcima u 2010. godini.

Prisutne su statistički opravdane razlike u masi 1000 sjemenki između istraživanih sorata lana, izuzev za Zagreb u 2010. i Križevce u 2008. i 2010. godini i između neprihranjenog i prihranjenog usjeva lana, izuzev za Zagreb u 2009. i 2010. godini i Križevce u 2010. godini. Najveće mase 1000 sjemenki imale su sorte Viking, Venica i Electra. 
Jasminka Butorac i sur.: Utjecaj gnojidbe dušikom na prinos

i sastavnice prinosa sjemena nekih sorata predivog lana

\title{
THE EFFECT OF NITROGEN FERTILIZATION ON YIELD AND YIELD COMPONENTS ON SOME FIBER FLAX VARIETIES
}

\author{
SUMMARY
}

This paper presents the results of the achieved yield and yield components of fiber flax seed (number of plants per $\mathrm{m}^{2}$, number of capsules per plant, number of seed per capsules, 1000 seed weight) of five foreign varieties. The selected varieties were fertilized without and with different nitrogen rates $\left(0,30,60\right.$ and $\left.90 \mathrm{~kg} \mathrm{ha}^{-1}\right)$ in different time. Cultivar trials with fiber flax were set up in three years (2008-2010) and in two locations: at Zagreb on anthropogenized eutric cambisol and at Križevci on pseudogley on level terrain. The trials were carried out according to the RCBD in four replications.

According to the results of the three-years research into the yield and yield components of fiber flax seed, significant differences were established among the varieties and among the added nitrogen rates under study. The varieties Viking, Venica and Electra were recorded higher values of investigated traits. The optimal nitrogen rate for fiber flax according to the obtain results will be $30 \mathrm{~kg}$ nitrogen $\mathrm{ha}^{-1}$.

Key words: fiber flax, varieties, nitrogen fertilization, seed yield, yield components

\section{LITERATURA - REFERENCES}

1. Andrassy Maja, Pezelj Emira, Butorac Jasminka, 2004. Povratak proizvodnji predivog lana. Tekstil 53 (8): 385-391.

2. Andrassy Maja, Šurina Ružica, Butorac, Jasminka, 2010. Influence of agroecological conditions on the properties of flax fibers in Croatia. $5^{\text {th }}$ International Textile, Clothing and Design Conference. Dubrovnik, p. 32-37.

3. Butorac, Jasminka, Pospišil, M., Mustapić, Z, 2003. Analiza gospodarskih i morfoloških svojstava predivog lana. 38. znanstveni skup hrvatskih agronoma s međunarodnim sudjelovanjem, Opatija, str. 399-402.

4. Butorac, Jasminka, Pospišil, M., Mustapić, Z., 2004. Prinos i udio vlakna predivog lana u uvjetima suše. 39. znanstveni skup hrvatskih agronoma s međunarodnim sudjelovanjem, Opatija, str. 563-566.

5. Butorac, Jasminka,Pospišil, M., Mustapić, Z., Zorić, D., 2006a. Procjena važnijih agronomskih i morfoloških svojstava sorti predivog lana pri različitoj gustoći sjetve. Sjemenarstvo 23(5/6): 437-445.

6. Butorac, Jasminka,Pospišil, M., Mustapić, Z.,2006b. Utjecaj gustoće sjetve na neka morfološka i fenološka svojstva sorti predivog lana. Sjemenarstvo 23(5/6): 447-456. 
7. Butorac, Jasminka,Pospišil, M., Mustapić, Z., Duvnjak, Ivana, 2009. Procjena agronomskih i morfoloških svojstava sorata predivog lana bez prihrane i s prihranom dušikom. Sjemenarstvo 26(3-4): 119-129.

8. Butorac, Jasminka, Pospišil, M., Mustapić, Z., Marković, Zvjezdana, 2010a. Utjecaj prihrane dušikom na neka morfološka i fenološka svojstva sorata predivog lana. Sjemenarstvo 27(1-2): 19-29.

9. Butorac, Jasminka, Šurina, Ružica, Andrassy, Maja, Augustinović, Zvjezdana, Pospišil, M.,2010b. Some agronomic and textile properties of flax cultivated in Croatia (Križevci). $5^{\text {th }}$ International Textile, Clothing and Design Conference. Dubrovnik, p. 42-47.

10. Butorac, Jasminka, Šurina, Ružica, Andrassy, Maja, Pospišil, M., Augustinović, Zvjezdana, Brčić, Marina, 2011. Utjecaj dužine vegetacije kultivara predivog lana na morfološka i tekstilno-tehnološka svojstva. 46. hrvatski i 6 . međunarodni znanstveni simpozij agronoma. Opatija, str. 723-727.

11. Butorac, Jasminka, Augustinović, Zvjezdana, Šurina, Ružica, Pospišil M., 2012 . Utjecaj stupnja zrelosti na prinos i udio vlakna predivog lana. 47. hrvatski i 7. međunarodni znanstveni simpozij agronoma. Opatija, str. 464-468.

12. Butorac, Jasminka, Pospišil, M., 2013 . Prinos i sastavnice prinosa sjemena predivog lana u ovisnosti o sorti i gnojidbi dušikom. 48. hrvatski i 8. međunarodni znanstveni simpozij agronoma. Dubrovnik, str. 462-466.

13. Cremaschi, D., Fontana, F., Vender, C., Maestrini, C., Natarelli, L., 1996. Effects of nitrogen fertilizer on flax (Linum usitatissimum L.) cultivars. Rivista Agronomia 30:252257.

14. Da enekindt, A., 2003. Belgische rassenlijst vezelvlas 2002. Vlas Berichten 4:1-4.

15. Les, M., Gauca, C., Morarescu, R., Vasiliu, C., 1977. Effect of some agronomic measures on yield of flax for fibre and oil. Cercet Agron Moldova 2:99-104.

16. Pasković, F., 1957 . Morfološka i tehnološka svojstva nizozemskih sorti lana. Tekstil 4:309326.

17. P a velek, M., 2001. New varieties - Venica. Czech J Genet Plant Breed 37:103-104

18. Pospišil, M., Butorac, Jasminka, Gojšić, Tea, 2004. Lan - zaboravljena, a korisna kultura. Gazophylacium 9(3-4):81-86.

19. Rossini, F. D., Antuono, L. F., Casa, R., 1997. Effects of sowing date and nitrogen fertilizer application on fibre flax seed production in central Italy. Sementi-Elette 43(2):17-23

20. Š i m e tić, S., 1995. Mogućnosti proizvodnje sjemena lana i njegova upotreba. Sjemenarstvo 12 (2-3):213-222.

21. Šurina, Ružica, Butorac, Jasminka, Andrassy,Maja, 2011. Ovisnost svojstava vlakana o svojstvima biljke lana. Tekstil 60(2-3):87-101.

22. Šurina, Ružica, Andrassy, Maja, Butorac, Jasminka, 2012. An interdisciplinary approach to flax research. $12^{\text {th }}$ World Textile Conference AUTEX 2012. Zadar, p. 181-186.

23. Zedan, S.Z., Kineber, M.E., Mostafa, S.H., 1999. Response of flax to potassium and nitrogen fertilization under sandy soil conditions. Egyp J Agric Res 77:729-743.

Adresa autora - Authors' address:

Prof. dr. sc. Jasminka Butorac

Prof. dr. sc. Milan Pospišil

Sveučilište u Zagrebu, Agronomski fakultet

Zavod za specijalnu proizvodnju bilja

Svetošimunska cesta 25

10000 Zagreb

E-mail:jbutorac@agr.hr

Dr. sc. Zvjezdana Augustinović

Visoko gospodarsko učilište u Križevcima

Milislava Demerca 1

48260 Križevci
Primljeno - Received: 21. 02.2013. 
